\title{
Intestinal Parasitic infections and Demographic status of school children in Bhopal region of Central India.
}

\author{
Tripathi Kiran*, Nema Shashwati, Bankwar Vishal, Dhanvijay Ashok kumar \\ ${ }^{I}$ M.Sc. Ph.D Professor Dept. of Microbiology L.N.Medical College and Research Centre \\ Bhopal (M.P.) India \\ ${ }^{2}$ MD Associate Professor Dept. of Microbiology L.N.Medical College and Research Centre \\ Bhopal (M.P.) India \\ ${ }^{3}$ MD Associate Professor Dept. of Preventive \& Social Medicine L.N.Medical College and Research Centre \\ Bhopal (M.P.) India \\ ${ }^{4}$ MD, Ph.D Professor and Head Dept. of Microbiology L.N.Medical College and Research Centre \\ Bhopal (M.P.) India
}

\begin{abstract}
:
Background: School going children of age 6-12 years are the prime victims of intestinal parasitic infections. There is scant information available on the prevalence and distribution of intestinal parasites among school children in Bhopal region of Central India.
\end{abstract}

Aim: To study, (a) prevalence and types of intestinal parasites in school children (b) Demographic status and sanitary habits of school children.

Materials and Methods: Cross sectional study was conducted in 300 rural and 300 urban school children of age 6-12 years. Data collected from their parents on demographic factors and behavioral habits. As consent was obtained only from rural school, stool samples of rural school children were examined for parasites by saline and iodine wet mount.

Results: The prevalence of intestinal parasitic infection was 40.7\%. Giardia intestinalis was the commonest protozoa found (43.44\%). Among helminths, Ascaris lumbricoides was predominantly detected $(9.84 \%)$. Literacy rate of head of family was $85 \%$ and $1.67 \%$ in rural and urban school children respectively. $49.33 \%$ used cloth filter and $41.66 \%$ used plain water for drinking in rural area while $15 \%$ used cloth filter and $34.66 \%$ used plain water for drinking in urban area. $7.33 \%$ of children from rural area and $3.0 \%$ children from urban area used open field for defecation. Dirty untrimmed nails were found in $86.23 \%$ of rural and $28.66 \%$ of urban school children.

Conclusion: Burden of parasitic infections and poor sanitation are still important public health problems in school children of our region. Creating awareness about health, improving sanitation level and promotion of de-worming could reduce intestinal parasitic infestation.

Keywords: Intestinal parasitic infections, school children, rural and urban

\section{Introduction:}

Intestinal parasitic infections are endemic especially in tropical and subtropical countries. It is estimated that more than two billion people are infected with intestinal parasites and nearly 300 million infected patients are severely ill. ${ }^{[1]}$ Children are the prime victims of intestinal parasitism that affect their physical development, school attendance and ability to learn. ${ }^{[2]}$ These parasites dwell in the gastrointestinal tract in humans and other animals. ${ }^{[3]}$ These heavily infected individuals are the prime source of environmental contamination. ${ }^{[4]}$ The high prevalence of these infections is closely related with poverty, poor environmental hygiene and poor health services. ${ }^{[5,6]}$

Like other developing countries intestinal parasitic infections are a major health problem in India. Although studies have been conducted among tribal pre-school children of Madhya Pradesh, ${ }^{[7]}$ there is insufficiency of epidemiological data on the prevalence of intestinal parasites in school going children of Bhopal region situated in Central India. Moreover, it is important to monitor the problem of intestinal parasitic infections and the factors related to it periodically and to tackle it in the interest of public health. Therefore the present study was planned to evaluate the prevalence and distribution of intestinal parasitic infections among school children of rural and urban areas of Bhopal region of Central India. In addition to this, associated sociodemographic and environmental factors as well as behavioral habits of school children were also studied. 


\section{Materials and Methods:}

1) Study design: A cross sectional study was planned after obtaining permission from Institutional ethics committee.

2) Study period: The study was conducted between July-August 2013 after obtaining approval from the school Principal.

3) Study group: This study was conducted among 300 children (6-12 years of age) each from rural school at Kajli Kheda and urban school situated in Kolar region of city Bhopal. Written informed consent was obtained from the parents of the children in local language. In addition, proforma containing structured questionnaire related to socio- demographic factors, environmental factors and behavioral sanitary habits was also given to the parents of the children to write the requested information. In case of parents who could not read or write, their proforma was written with the help of class teacher.

4) Specimen Collection: A small screw capped plastic bottle with scoop was provided to each of the participant for collection of stool sample. The stool samples were collected and brought to the laboratory for processing. All the containers along with specimens were properly labeled with name, sample number and date respectively. The Principal and parents of urban school children did not approve for the collection of stool sample and therefore their samples could not be collected for the study.

5) Specimen Processing ${ }^{[8]}$

(A) Macroscopic examinations: Each stool specimen was macroscopically examined for presence of mucus, blood or for presence of any parasite.

(B) Microscopic examinations: The recognition of intestinal parasites was observed by using a binocular microscope under 10Xand confirmed by observing under 40X.

(i) Saline wet mount: Approximately $2 \mathrm{mg}$ of stool sample was picked up using a wooden stick and mixed with a drop of $0.9 \%$ normal saline on a glass slide with applicator stick. The preparation was covered with a cover slip and observed under the microscope.

(ii) Iodine wet mount: Approximately $2 \mathrm{mg}$ of stool sample was picked up using a wooden stick and mixed with a drop of dilute Lugol's iodine. It was covered with a cover slip and observed under the microscope.

\section{Results:}

The overall prevalence of intestinal parasitic infection was $40.7 \%$ among school going children of rural area [Table 1].

$85.24 \%$ of infections were due to Protozoan parasites, while intestinal helminths were detected in only $18.8 \%$ of rural school children. Giardia intestinalis was the commonest pathogenic protozoa found in $43.44 \%$ children followed by Entamoeba histolytica in $25.4 \%$ children. Among intestinal helminths, prevalence rate of Ascaris lumbricoides and Ancylostoma duodenale infections were found to be $9.84 \%$ and $4.92 \%$ respectively [Figure 1].

Socio-demographic characteristics of rural and urban school children are as shown in Table 2. Illiteracy rate of the head of the rural and urban school children were found to be $85 \%$ and $1.67 \%$ respectively. $69.33 \%$ children of rural school and 3.33\% children of urban school lived in non-concrete kuccha houses. It was observed that $52.67 \%$ of children used borewell and $23.67 \%$ used openwell water for drinking purpose in rural area, whereas only $33.0 \%$ used bore well and $2.0 \%$ of them used open well as source for drinking water in urban area. $21.33 \%$ used municipal water for drinking in rural area and $57.0 \%$ in urban area.

$49.33 \%$ children used cloth filter for processing drinking water and $41.66 \%$ used plain water for drinking in rural area and with comparison only $15 \%$ used cloth filter for processing drinking water and $34.66 \%$ used plain water for drinking in urban area. In rural area, $73.33 \%$ children and in urban area only $3.0 \%$ used open field for defecation. In $92.0 \%$ rural and $99.0 \%$ urban area, study subjects used soap and water for hand wash after defecation. Dirty untrimmed nails were seen in $86.23 \%$ of rural school children and $28.66 \%$ in urban school children. 3.0\% of children from rural area were found to have the habit of Pica. [Table3].

\section{Discussion:}

Intestinal parasitic infections constitute a global health problem in various developing countries mainly due to fecal contamination of water and food. ${ }^{[9]}$ Hot and humid climate, environmental and sociocultural factors enhance parasitic transmissions. ${ }^{[10,11]}$

The present study was conducted to see the overall prevalence of intestinal parasitic infections and also the prevalence of each parasite in school children. Unfortunately the principal of urban school did not approve for the collection of stool samples, therefore, intestinal infections in urban school children could not be detected. In our study the prevalence of intestinal parasites among school children of rural area was found to be $40.7 \%$ [Table 1]. This rate was comparable to the previous studies conducted by Dakshina B et al ${ }^{[12]}(38 \%)$ and Sehgal $\mathrm{R}$ et al $(42.8 \%)^{[13]}$. However, Dambhare DG et al ${ }^{[14]}$ found intestinal parasitic infection in only $7.56 \%$ of school 
children in rural area. The dispersed distribution might be due to the heterogeneity in social, behavioral and special factors affecting the degree of express of infection.

Distribution of intestinal parasites in school going children of rural area [Figure1] shows that protozoan parasitic infections were significantly higher $(85.24 \%)$ than the intestinal helminthic infections (18.8\%). Similar finding was reported in previous studies conducted by Misra $S$ et al ${ }^{[15]}$ and Panda $S$ et al. ${ }^{[16]}$ High prevalence rate of protozoan parasite showed that the transfer of infection between persons through food or water is high and this proves that there is high level of contamination by human faeces. In our study, Giardia intestinalis was the commonest cause of parasitic infection. It was also the commonest protozoa found in other Indian studies. ${ }^{[13,17]}$ In a study conducted by Dakshina B et al, ${ }^{[12]}$ Entamoeba histolytica was the commonest protozoa isolated among children in rural areas. Among helminths, Ascaris lumbricoides was the commonest parasite found in this study. The same was reported by Bora D et al ${ }^{[18]}$ and Saifi MA et al. ${ }^{[19]}$ However, infection by Hymenolepis nana was not detected in our study while it was detected in previous studies conducted from other parts of India. $[13,16,17]$ The variations in prevalence of infection in different studies could be attributed to the time of study and geographical differences in the area.

Sociodemographic and environmental factors were also studied in school children [Table 2]. It was found that illiteracy rate of head of the family in rural school children was $85 \%$ which was much higher than in urban school children (1.67\%). In a study conducted from Vizianagar, $72.2 \%$ of the father and $97.4 \%$ of mothers were found to be illiterate. ${ }^{[16]}$ Similar study in Sanilurfa Province of Turkey showed illiteracy rate of $18.1 \%$ among fathers and $70.4 \%$ in mothers of school children. ${ }^{[20]}$ Illiterate father cannot hire skilled jobs and tend to have lower incomes which lead to poor living conditions and poor sanitary habits aggravating their wards growth and parasitic infections. In a study conducted by Celikosoz et al, ${ }^{[21]}$ higher percentages of children of uneducated mothers were found positive for intestinal parasites (69\%). Okayay et al ${ }^{[22]}$ observed that mother's education was important for the proper guidance of the growing children. Educated mothers can train their children well and maintain a better health than the uneducated mothers.

$67.33 \%$ of houses built in rural areas were mainly of Kuccha type (non-concrete) [Table 2]. Such type of houses is built in close vicinity without proper sanitation and drainage measures. This contributes to poor hygiene and prevalence of parasitic infections in these areas. It was also noted that $71 \%$ of parents used openwell and $52.67 \%$ used borewell in rural area as source of drinking water. Since these wells are dug at the shallow level, they come in contact with open drain or canal and provide optimum conditions for survival and development of eggs of parasites like Ascaris lumbricoides ${ }^{[23]}$ Stephenson LS et al ${ }^{[24]}$ and Oyewole F et al ${ }^{[25]}$ have also found association of parasitic infection with intake of ring-well water and river water.

Different behavioral habits of school children are shown in Table 3. Water contaminated by eggs and cysts of parasites act as a major source for transmission of intestinal parasitic infections. ${ }^{[8]}$ Different studies have proved that untreated water is the main cause of intestinal infections. ${ }^{[14,26]}$ In our study, it was observed that $41.66 \%$ children used plain water and $49.33 \%$ children used cloth filtered water for drinking. Such untreated water may be the main source of intestinal parasitic infections in rural school children.

Majority of school children in rural area, (73.33\%) used open field for defecation. This rate was only $3 \%$ in urban population. Defecating in the surrounding fields leads to the contamination of water supply and can cause intestinal parasitic infections. Surprisingly, it was found that hand washing practices after defecation were equally good in both rural and urban school children. Still, the prevalence of parasitic infection was found to be high. This may be attributed to faulty hand washing techniques. In our study, $86.33 \%$ of rural school children were found to have dirty untrimmed nails; this rate was only $28.66 \%$ in urban school children. Dambhare et al ${ }^{[14]}$ observed dirty untrimmed nails in $38.4 \%$ of school children in rural area, out of which $10.6 \%$ children were found to have intestinal parasitic infections. Moreover, 3.0\% of rural school children in the present study developed the habit of Pica. Presence of such unhygienic behavioral habits emphasizes the need for health education on personal hygiene mainly in rural areas of India. In addition to this, regular monitoring of these practices by school teachers is also suggested.

\section{Conclusion:}

The prevalence of $40.7 \%$ parasitic infections in this study shows that intestinal parasitic infections are still important public health problems in our region. These infections were found to be due to low standards of personal hygiene, faulty technique of hand washing, non-usage of sanitary latrine, poor sanitation and an illiterate population. A multisectoral control approach of mass deworming programmes and hygiene education to the students and parents is required to control parasitic infections among school children of this region.

Our study also highlights the fact that in spite of the easy availability of antiprotozoal and antihelminthic drugs, these conditions are not yet eradicated. Therefore, there is a need of time to time surveys and to take appropriate full proof preventive measures to prevent intestinal parasitic infections especially in rural areas. 


\section{References:}

[1]. Mehraj V, Hatcher J, Akhtar S, Rafique G, Beg MA. Prevalence and factors associated with intestinal parasitic infection among children in an urban slum of Karachi. PLoS One. 2008; 3(11): e3680.

[2]. Jasti A, Ojha SC, Singh YI. Mental and behavioral effects of parasitic infections: a review. Nepal Med Coll J. 2007; 9(1): 50-6.

[3]. Haque R. "Human intestinal parasites". Journal of Health, Population and Nutrition 2007; 72(4): 387-391.

[4]. Bundy DAP and Guyatt HL. School for health: Focus on health, education and the school-age child. Parasitol Today. 1996; 12: 117.

[5]. Montresor A, Crompton DWT, Hall A, Bundy DAP and Savioli L. Guidelines for the evaluation of soil transmitted helminthsiases and schistosomiasis at community level. World Health Organisation, Geneva, WHO/CTC/SIP/98 1998.

[6]. Albonico M, Crompton DWT and Savioli L. Control strategies for human intestinal helminth infections. Advanced Parasitology 1999; 42:276-341.

[7]. Rao VG, Yadav R, Bhondeley MK, Das S, Agarwal MC, Tiwary RS. Worm infestation and anaemia: a public health problem among tribal pre- school children of Madhya pradesh. J commun Dis. 2002; 34(2):100-5.

[8]. Parija S C. Text book of Medical Parasitology. $3^{\text {rd }}$ ed. Common Laboratory Methods in Parasitilogy. Stool examination; p. 362.

[9]. Odu NN, Akujobi CO, Maxwell SN and Nte AR. "Impact of mass deworming of school children in rural communities in Rivers State,Nigeria: option for programme sustainability." Acta Parasitologica. 2011;2:20-24.

[10]. Mordi RM and Ngwodo POA. "A study of blood and gastro-intestinal parasites in Edo state." African Journal of Biotechnology 2007; 19(6): 2201-2207.

[11]. Alli JA, Kolade A F, Okonko IO et al. "Prevalence of intestinal nematode infection among pregnant women attending antenatal clinic at the University College Hospital, Ibadan, Nigeria”. Advances in Applied Science Research. 2011;2:1-13.

[12]. Bhist D, Verma AK and Bhardwaj HHD. Intestinal parasitic infestation among children in a semi-urban Indian population. Trop Parasitol.2011; 1(2): 104-107.

[13]. Sehgal R, Gogulamudi V. Reddy, Jaco J. Verweij, Atluri V, Subba Rao. Prevalence of intestinal parasitic infections among school children and pregnant women in a low socio-economic area, Chandigarh, North India. Reviews in infection. 2010; 1(2):100-103.

[14]. Dambhare D G, Bharambe M S, Garg B S. Intestinal Parasites Prevalence and Related Factors among School Children in the Rural Area of Central India. J. Commun. Dis. 42 (4) 2010: 281-286.

[15]. Misra Shobha, Duttaroy Bithika, Shroff Bhavesh. The prevalence of intestinal parasitic infections in the urban slums of a city in Western India. Journal of Infection and Public Health 2013; 6(2): 142-149.

[16]. Panda S, Rao UD, Sankaram KR. Prevalence of Intestinal Parasitic Infections among School Children in Rural Area of Vizianagaram. IOSR Journal of Pharmacy and Biological Sciences 2012; 3(3): 42-44.

[17]. Aher A, Kulkarni S. Prevalence of intestinal parasites in school going children in a rural community. International J of biomedical research 2011;2(12):605-607.

[18]. Bora D, Meena VR, Bhagat H, Dhariwal AC, Shivlal. Soil transmitted helminthes, Prevalence in school children of Pauri Garhwal district, Uttaranchal State. J Commun Dis 2006; 38: 112-4.

[19]. Saifi MA, Wajihullah. Intestinal parasitic infestation in school children of Ujhani, Budaur. Journal of Parasitic Diseases. 1997; 25(1): 26-9.

[20]. Ulukanliqil M, Seyrek A.Demographic and socio-economic factors affecting the physical development, haemoglobin and parasitic infection status of schoolchildren in Sanliurfa province,Turkey . Public Health 2004;118(2):151-8.

[21]. Celiksöz A, Güler N, Güler G, Oztop AY, Degerli S. Prevalence of intestinal parasites in three socioeconomically different regions of Sivas. Turkey. J Health Popul Nutr. 2005; 23(2):184-91.

[22]. Okyay P, Ertug S, Gultekin B,Onen O and Beser E. Intestinal parasites prevalence and related factors in school children, a western city sample-Turkey. BMC Public Health 2004; 4:64.

[23]. Awasthi s, Verma T, Kotecha PV, Venkatesh V, Joshi V, Roy S. Prevalence and risk factors associated with worm infestation in Pre- School children (6-23 Months) in selected blocks of Uttar Pradesh and Jharkhand, India. Indian J Med Sci. 2008; 62(12): 484490 .

[24]. Stephenson LS, Latham MC, Adams EJ, Kinoti SN. Weight Gain of Kenyan School Children Infected with Hookworm, Trichuris trichura and Ascaris lumbricoides is improved following Once or Twice-Yearly Treatment with Albendazole. J Nutr. 1993; 123: 656-65.

[25]. Oyewole F, Ariyo F, Oyibo WA, Sanyaolu, Faweya T, Monye P, et al. Helminthic reduction with albendazole among school children in riverine communities of Nigeria. J Rural Trop Public Health 2007; 6: 6-10.

[26]. Escobedo AA, Canete R, Nunez FA. Prevalence, Risk Factors and Clinical Features Associated With Intestinal Parasitic Infections in Children from San Juan Y Martinez, Pinar del Rio, Cuba. West Indian Med J. 2008; 57 (4): 377.

Figure 1: Distribution of intestinal parasites 

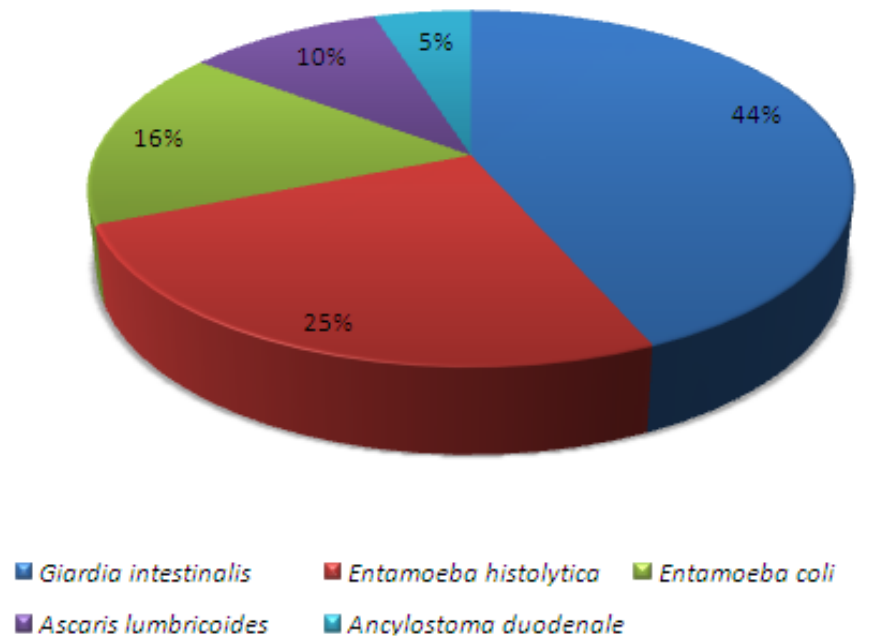

Table 1: Prevalence of Intestinal Parasitic infection in school going children of rural area

\begin{tabular}{|l|l|l|l|l|}
\hline $\begin{array}{l}\text { Total stool sample } \\
\text { tested }\end{array}$ & $\begin{array}{l}\text { No of samples positive } \\
\text { for Parasites }\end{array}$ & Percentage of parasites & $\begin{array}{l}\text { No of samples negative } \\
\text { for parasites }\end{array}$ & Percentage of parasites \\
\hline 300 & 122 & $40.7 \%$ & 178 & $59.3 \%$ \\
\hline
\end{tabular}

Table 2: Socio-demographic and environmental factors

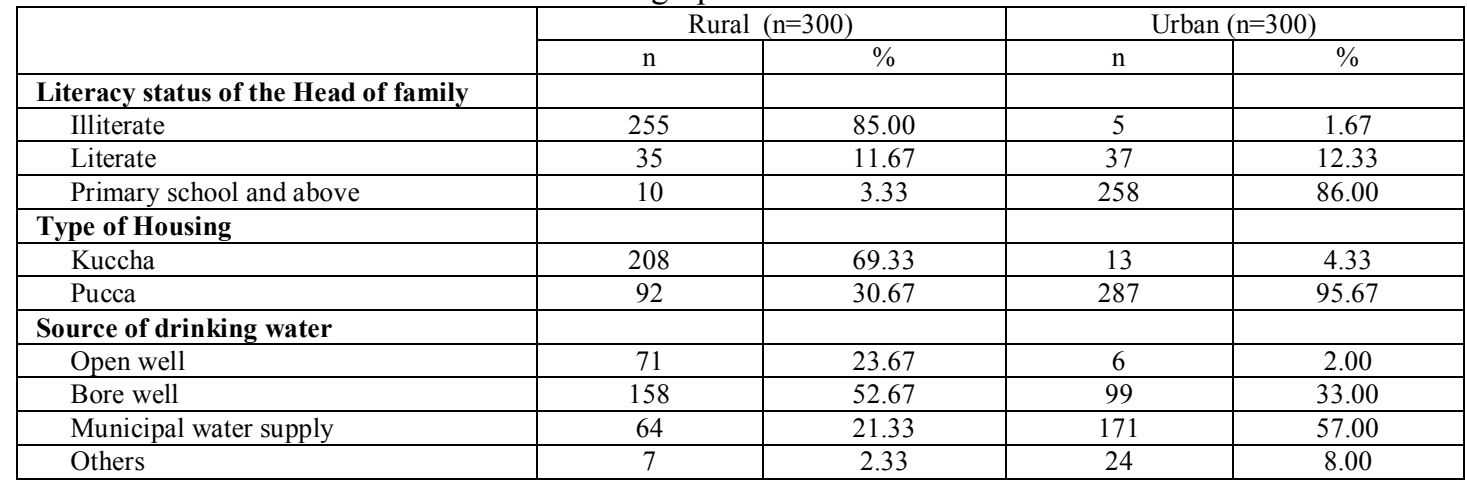

Table 3: Behavioral and sanitary habits

\begin{tabular}{|c|c|c|c|c|}
\hline & \multicolumn{2}{|c|}{ Rural $(n=300)$} & \multicolumn{2}{|c|}{ Urban $(n=300)$} \\
\hline & $\mathrm{n}$ & $\%$ & $\mathrm{n}$ & $\%$ \\
\hline \multicolumn{5}{|c|}{ Mode of processing drinking water } \\
\hline Plain water & 125 & 41.66 & 104 & 34.66 \\
\hline Cloth filter & 148 & 49.33 & 45 & 15 \\
\hline Filtration & 27 & 9.00 & 151 & 50.33 \\
\hline \multicolumn{5}{|l|}{ Defecation } \\
\hline Open field & 220 & 73.33 & 9 & 3.00 \\
\hline Sanitary latrine & 80 & 26.67 & 291 & 97.00 \\
\hline \multicolumn{5}{|c|}{ Hand washing after defecation } \\
\hline Mud and water & 24 & 8.00 & 3 & 1.00 \\
\hline Soap and water & 276 & 92.00 & 297 & 99.00 \\
\hline Dirty untrimmed nails & 259 & 86.33 & 86 & 28.66 \\
\hline Pica & 09 & 3.0 & 0 & 0 \\
\hline
\end{tabular}

